\title{
AUTISM AMONG PRIMARY SCHOOL PUPILS IN BENIN METROPOLIS: IMPLICATIONS FOR COUNSELLING
}

\author{
AUDU, E. I. Vivian \\ $\&$ \\ EGBOCHUKU, O. Elizabeth PhD \\ Department of Educational Psychology and Curriculum Studies, \\ Faculty of Education, \\ University of Benin, Benin City. \\ email: mamandidi@yahoo.co.uk
}

\begin{abstract}
The study investigated the existence of autism among primary school pupils in Benin City. The rationale for this study was as a result of the growing concern about autism worldwide. Knowledge about this disorder is still limited. Most parents and teachers still do not understand its diagnosis, symptoms and effects at home and school environments. This lack of understanding of this complex neuro-developmental disorder that affects a child's social interaction, communication and behaviour has become pertinent for the present study to be carried. Survey research design was adopted; three (3) research questions were raised. The samples were 131 teachers. Descriptive statistics was used to analyse the data collected. The results revealed that autism exists among the sample used, that boys are more afflicted with the disorder than girls. Autism differs in occurrence with the age of pupils and the level of awareness of parents is low. Based on the findings, recommendations and implications for counselling were presented.
\end{abstract}

Keywords: Autism, teachers, parents, schools, Nigeria.

\section{Introduction}

One of the instruments for attending to pupils' or students' needs is guidance and counselling services in the school. Many definitions of the words "guidance" and "counselling" exist but they all point to the fact that guidance is a comprehensive system of services and programmes which are designed to help individuals to understand themselves, their interest, needs and abilities so that they can grow and develop into physically, psychologically and socially healthy human personalities while counselling is a process by which a person is assisted to confront 
his or her social and psychological problems through interaction with another well-informed person, usually a counsellor or psychologist (Egbochuku 2008). In the primary school in Nigeria, we are dealing with children whose ages range from 6 to 12 or 13 years and their need areas include personality development and academic success.

There is much crisis in Nigerian primary schools; this could be as a result of her failure or inability to satisfactorily apply the precepts and principles of guidance and counselling in the teaching and learning environment. Critical elements in the crisis include pupils' poor attitude to study. Indiscipline, misconduct, aggression and violent behaviour among pupils have also been reported.

Counselling pupils for effective learning, improved academic performance and well rounded personality should be the major preoccupation of school counsellors and teachers. Unfortunately, the actual practice is quite a distance from the precepts and expectations. For example, pupils with learning difficulties and those who are stressed because of emotional problems are usually not identified for more personalized counselling by the teachers and the school authority. What most teachers do is to quickly label pupils into "bright" high achievers and "weak", "dull", "Dundee" under-achievers. In the area of general behaviour, pupils are generally perceived by teachers as troublesome and aggressive or quiet and withdrawn. Very often, teachers who label pupils as dull, Dundee, foolish, troublesome, aggressive etc are ignorant, unaware and misunderstand the causes of the pupil's academic, behavioural and social problems. The root causes of pupils' poor academic and exhibited maladaptive behaviour are not diagnosed nor are individualized remedies sought. It is important to investigate the root causes of the learning difficulties of each child. The causes may include the possibility of inherited or genetic factor, brain abnormalities, psychological and emotional difficulties.

One aspect that has not been explored is the possibility that some of these labelled pupils may have communication, social interaction and creative or imaginative impairments that are reminiscent of autism. Autism is a brain development childhood disorder characterized by impairments in social interaction, communication, restricted and repetitive behaviour, all manifesting before the age of three and continues till adulthood. Autism has been identified as one of the five Pervasive Developmental Disorders (PDD), (World Health Organization, 2006). The other types include Asperger syndrome, Rett syndrome, childhood disintegrative disorder and pervasive developmental disorder not 
otherwise specified (PDD-NOS). There is increasing concern about the prevalence of autism in many parts of the world including some underdeveloped and developing societies. In Okey-Martins' (2007) review, he estimated a prevalence of one to two cases per 1,000 people for autism, and about six per 1,000 for mild autism spectrum disorder (ASD). He further found that ASD is four times more prevalent in boys than girls, and that autism knows no racial, ethnic or social boundaries. He opined that family income, life style, and educational levels do not affect the chance of autism occurrence.

Since 1980s, the number of individuals who are known to have autism has increased dramatically, partly due to changes in diagnostic practice but the actual prevalence is not resolved (Newschaffer, Croen, \& Daniels, 2007). The efforts to recognize autism as a disability in its own class and to address its many challenges started in the United States in early 1940's through 1960's till date. South Africa began this effort in Africa when a medical doctor became aware of the extent of the problem of autism in Cape Town in 1960. The first school for autistic learners was opened in 1970 in Cape Town. South Africa now has five such schools.

The level of awareness is still low in Nigeria. Children with autism are sometimes referred to as mentally retarded, schizophrenic or suffering from maternal deprivation. Spiritual factors have also been used to explain its aetiology. Autistic children are either not diagnosed or wrongly diagnosed. Most parents, because of lack of awareness, hide their autistic children at home because of the fear of being stigmatized or discriminated against. Other individuals with autism are labelled retard, dumb or deaf. Okey-Martins (2007) opined that lack of awareness of this disorder has resulted in most sufferers of autism ending up in the streets as insane people in the rural areas. According to him, the children are at risk because they are not diagnosed early; regular schools reject the children, those accepted are labelled and not given opportunity to develop at their pace; the adults end up in the streets as "mad" people and parents are completely left to bear the responsibility. Children need not to be blind, lame, dumb, mentally retarded before they can get appropriate services and special education. There are no government facilities for individuals with autism, but the blind and physically challenged have many services and schools. According to Okey-Martins, (2007), current estimate for children who are yet to be diagnosed in Nigeria is over 190,000 .

The prevalence rates has risen from 1 in 10,000 in 1943 to 1 out of every 150 births according to statistics from American Centres for Disease 
Controls (Daily Sun, 2007). Researchers have not succeeded in identifying the causes of autism and how it affects most parts of the brain during infancy or childhood. Scientists are also not certain of the causes but they suggest that both genetics and the environment are likely to play a role. There is evidence that early identification and intervention can help individuals overcome many of the symptoms and lead a productive and successful life. Autism spectrum disorder (ASD) is treatable through behavioural and educational intervention.

At the moment, there is no recorded report of the presence of autism among students or pupils in Edo State in spite of the noticeable increase of primary schools and the number of pupils in these schools as a result of inclusive education that is being practised in Nigeria. This is therefore the focus of this study: to investigate if there are autistic pupils in Edo state, and if yes, which sex is more affected. This will help to expose parents, teachers, counsellors and the public to the knowledge of this disorder.

\section{Statement of the Problem}

Autism, as a development brain disorder in children, has not received the due attention it deserves from government, counselling psychologists and teachers. There are lots of gaps in our understanding of autism and its management in primary schools in this part of the world. Autism is a brain disorder that is present in all races and classes of people. Literature has it that about 35 million people worldwide are known to have this disorder. Worse still, every 20 minutes, a child is diagnosed with autism disorder, equivalent to about 30 children daily.

The prevalence and other facts about autism all over the world are frightening. Current projections indicate a risk that the prevalence may be moving towards 1 in 50 in 10 years (Nwokolo, 2007). The number of reported cases of autism increased dramatically in the 1990s and early 2000s prompting researches on autism. This increase is largely attributable to changes in diagnostic practices, referral patterns, availability of services, age at diagnosis and public awareness. It is a pervasive developmental disorder that impairs an individual's ability to communicate, learn and get along with others. There is a current estimate of about 190,000 children in Nigeria that have not been diagnosed and there is low level of awareness about the disorder (Nwokolo, 2007). Autism was once a rare disorder but had become so common that it is reputed as one of the fastest growing childhood disorders and the third most common developmental brain disorder. Autism is not an "Oyibo 
wahala" (white man problem); it can occur in any family irrespective of race, social status or religion. There is no known medical cure and researchers are yet to identify exact cause(s) of autism.

In Nigeria, professional care is practically not available for autistic children in schools and homes. Teachers and parents are not aware of autism and as a result, they don't have appropriate training and skills. To reduce the effects of this disorder, children with autism need to be assisted to overcome their difficulties, and live like normal children. Autistic children lack communication, social interaction, and have short attention span. They also exhibit temper tantrums and restrictive/repetitive behaviour. As a result of these problems, teachers may have difficulty in teaching them together with other pupils in class. Due to the learning and behaviour problems created by children with autism in class, and since the prevalence of this disorder is not known, this study seeks to investigate the existence of Autism among primary school pupils in Benin City, Edo State.

To guide this study, three (3) research questions were raised.

\section{Research Questions}

1. Does autism exist among primary school pupils in Edo state?

2. Are there more boys with this disorder than girls in primary schools in Edo state?

3. Does autism differ in occurrence with the age of the pupils?

\section{Method of study}

The study adopted the survey research design. The population of this study consists of all public primary school teachers in Benin City in Oredo Local Government Area of Edo State.

The sampling technique adopted for this study is simple random sampling technique. This meant that every teacher in Benin City had a chance of being selected as a subject in the sample. Twelve schools were randomly selected and then 10 percent of the teachers in these schools constituted the sample of teachers selected. A sample size of one hundred and thirty one (131) teachers was randomly selected from primary schools in Benin City.

Instrument used for the study consisted of a questionnaire titled "Autism among Primary School Pupils (APSPQ). Section A of the questionnaire is made up of demographic information and section $B$ is made up of twenty-two questions on autism among primary school 
pupils in Benin. The reliability of APSPQ was determined by administering it to teachers and workers in public schools who are not included in the sample. The pilot group was made up of twenty teachers and workers. The reliability procedure adopted the split half reliability test approach in which the APSPQ was administered to the pilot group to determine the internal consistencies of the items. The data obtained from the administration was analysed by separating the items to odd and even. A pair of scores was then obtained for each of the twenty parents or workers and teachers. The Pearson product correlation coefficient $(R)$ was applied to obtain an $r$ value that was then corrected using the Spearman Brown correction formula. A reliability correlation coefficient of $\mathrm{r} 0.76$ was obtained. The data generated from the respondents were addressed by answering the three research questions formulated for the study. The statistical method employed is descriptive in nature.

\section{Results and Discussion}

Research question 1: Does autism exist among primary pupils in Edo State?

Table 1: $\quad$ Response on occurrence of autism among pupils in Edo state

\begin{tabular}{|l|c|c|}
\hline \multicolumn{1}{|c|}{ Responses } & Frequency & Percent \\
\hline No & 93 & 71 \\
\hline Don't know & 08 & 6.1 \\
\hline Yes & 30 & 22.9 \\
\hline Total & 131 & 100.0 \\
\hline
\end{tabular}

Table 1 shows that $30(22.9 \%)$ of the respondents acknowledge the existence of autism, 93(71\%) claimed it does not exist, while 08(6.1\%) stated that they don't know. From Table 1 it shows that autism does exist among pupils in Edo state schools.

Research question 2: Are there more boys with this disorder than girls in primary schools in Edo State?

Table 2: Response on occurrence of autism by sex

\begin{tabular}{|l|c|c|}
\hline \multicolumn{1}{|c|}{ Responses } & Frequency & Percent \\
\hline No & 30 & 22.9 \\
\hline Yes & 101 & 77.1 \\
\hline Total & 131 & 100.0 \\
\hline
\end{tabular}


Table 2 shows that 101(77.1\%) of the respondents report that autism occurs more in males than in female while 30(22.9) report that it occurs more in females than in males. So, autism occurs more in boys than girls in primary schools in Edo State.

Research question 3

Does autism differ in occurrence with the age of the pupils?

Table 3: Responses on occurrence of autism by age

\begin{tabular}{|l|c|c|}
\hline Responses & Frequency & Percent \\
\hline No & 30 & 22.9 \\
\hline Don't know & 59 & 45.0 \\
\hline Yes & 42 & 32.1 \\
\hline Total & 131 & 100.0 \\
\hline
\end{tabular}

Table 3 shows 42 respondents which accounts for $32.1 \%$ of the respondents agreeing that autism become more severe with age, while 30 respondents which accounts for $22.9 \%$ disagree. So, autism does differ in occurrence by age.

\section{Discussion}

Table 1 revealed that autism exists among primary school pupils in Edo State. This does not agree with Okey's (2007) study, which labelled autism as a white man's disorder. His view could be as a result of low awareness in Nigeria, which could have led to wrong diagnosis putting autistic children at risk of being neglected. The attestation of $22.9 \%$ from the respondents of the existence of autism among primary school pupils in Edo State confirms the findings from American Centre for Disease Control and Prevention (2000) study that autism exists every where in the world. As a result of this finding, there is need to intensify the creation of knowledge and awareness of autism among the citizenry. This will help to stop the wrong labelling of autistic children.

Table 2 revealed that autism occurs more in boys than girls in the primary schools used in Benin City. The implication of this result is that autism exists among pupils in Edo state. The fact that autism occurs more in boys than girls is consistent with previous researches (CDC, 2000; Kennedy Krieger Institute, 2005; Newschaffer et al. 2007 and Autism Society of America in Wikipedia, 2008). These studies indicate that autism is four times more common in boys than girls and boys are also at higher risks of the disorder. 
The study further revealed that autism differs in occurrence by age. Autism is a spectrum disorder. In other words, the symptoms and characteristics of autism can present themselves in a wide variety of combinations, from mild to severe. Although, autism is defined by a set of behaviours, children and adults can exhibit any combination of the behaviours in any degree of severity. Two children, both of the same diagnosis, can act differently from one another. This finding is consistent with the study of Chairman, Taylor, Drew, Cockeril, Brown and Baird, (2005); they assessed twenty-six children diagnosed with autism at age 2, reassessed them at age 3 and 7 years in symptom severity, cognitive and language. They found that pattern of symptom change over time.

Autism is becoming a global epidemic. In a 2008 conference on the global epidemic of autism attended by first ladies in New York, Wright, a co-founder of Autism speaks gave a staggering statistics estimate that approximately one percent of the global population has autism, that is 67 million people worldwide. Nigeria has 190,000 children living with autism disorder. The first signs of autism are detected in the first three years of a child. Who does the child first make contact at this period of detection? It is the parents of course; this is why parents need to be aware of autism in order to take their children for early diagnosis and intervention therapies thereby minimizing the challenges and difficulties associated with symptoms of autism. The result of the finding is consistent with the African Network for the Protection against Child Abuse and Neglect (ANPPCAN) (2007) study that ascertained the level of knowledge and awareness on autism among workers and the public in Enugu State and Okey-Martins (2007) that the level of awareness about autism is low among the public. Low awareness about autism may increase the children's risk of the disorder.

\section{Implications for counselling}

i. Since autistic pupils are in schools, counsellors and teachers should take care of their needs in the teaching learning situation.

ii. The teachers should employ teaching methods that will accommodate autistic pupils and their challenges.

iii. Regular seminars or workshops should be organized by counsellors to create awareness of autism disorder.

iv. Counsellors and psychologists should come up with intervention programmes for parents and teachers to manage autistic pupils in the home and school environments. 


\section{Conclusion and Recommendations}

The study has revealed that not all the pupils in the public or regular schools in Benin metropolis are the same. Some of them are autistics who need special attention and treatment in order to get along with their peers and cope with their academic work in school. Autistic symptoms are detected before the child is 3 years old and the child's chance of getting it knows no racial, ethnic or social boundaries. It is four times more common in boys than girls. The symptoms of autism include deficit in communication and social interaction. Autistics resist change in their routines, exhibit temper tantrums or self-injurious behaviour and are aggressive. These behaviours create problems for the pupils and the teachers in the teaching learning process. The study further revealed that parents' level of awareness about autism disorder is low.

In view of the findings of this study, we recommend that awareness level of parents be increased to prevent problems at home and school environments. It is also recommended that more of this study should be carried out in order to create more awareness among parents and the public. Individualized Education Programme (IEP) for pupils with autism disorder should be established to meet their needs and challenges.

\section{References}

American Psychiatric Association (2000). Diagnostic criteria for 299.80. Asperger's Disorder, Diagnostic and Statistical Manual of Mental Disorders, $4^{\text {th }}$ ed., text revision.

Autism speaks (2008) UN Global focus on autism. New York

Bakere M. O., Ebigbo P. O Bakare M. O. and Menkiti N. C. (2008) Knowledge about childhood autism among health workers Nigeria Pub. Med Central Ltd.

Baron Chohen S. (2006). The hyper-systemizing, assortative mating theory of autism Prog. Neurophy Psychilary 30(5) 865.

Bodfish J.W, Symons F.J, Parker D.E, and Lewis M.H (2000). Varies of repetitive behaviour in autism: comparisons to mental retardation. J. Autism Dev. Disord 30(3) pp. 237-43.

Bootzin, R. R., Bower, G. H, Zajonc, R. B. and Hall, E. (1986) Psychology Today An Introduction, Random House, New York.

Brown M.J, Willis T. Omalu B and Leiker R. (2006). Deaths resulting from Hypocalcemia After Administration of Edetate disodium. Pediatrics 118(2) pp. 534-. 
Burgess A.F, and Gutstein S.E (2007). Quality of life for people with autism: raising the standard for avaluating successful outcomes. Child Adolesc Ment health 12 (2) 80-6.

Caronna E. B., Milunsky J. M., and Tager-Flusberg H (2008). Autism spectrum disorders: clinical and research frontiers. Arch Dis Child 93 (6) $518-23$.

Centre for Disease Control and Prevention (CDC), (1997). Definition of autism. Diagnostic.

Chairman T., Taylor E., Draw A., Cockerill H, Brown J. A. and Baird G. (2005) Outcome of 7 years of children diagnosed with autism at age 2: Predictive validity assessments conducted at 2 and 3 years of age and pattern of symptom change overtime London J. Child Psychol Psychiatry 46(5): 500 - 13.

Chakjrabarti S, Fombonne E (2001). Pervasive developmental disorders in preschool children. JAMA 285 (24): 3093 - 9.

Cohen D., Pichard N., and Tordjman S. (2005). Specific genetic disorders and autism: clinical contribution toward their identification. J. Autism Dev. Disorder 35(1) 103-16.

Croen L.A, Grether J.K, Iloogstrate J, and Selvin S (2003). The changing prevalence of autism in California. J. Autism Developmental. Disorder; 32: $207-15$.

Daily Sun (2007) The Sun News Online The sun publishing Ltd. Nigeria.

Davidoff L.L., (1987). Introduction to Psychology McGraw-Hill Book Company, New York.

Doja A, Roberts W. (2006), Immunizations and Autism: A review of the literature. Can J. Neural Sci. 33 (4) 341 - 6.

Dominick K. C., Davis N. O., Lainhart J., Tager -Flusberg H. and Folstein S. (2007). Atypical behaviours in children with autism and children with a history of language impairment. Res Dev. Disabil 28 (2) 14562.

Egbochuku, E. O. (2008). Guidance and counselling: A comprehensive text. University of Benin press, Benin-city.

Folstein S.E. Rosen Sheidley B. (2001). Genetics of autism: Complex aetiology for a heterogeneous disorder, Nat Rev. Genet 2 (12) pp. 943-55.

Fombonne E. (2005). Epidemiology of autistic disorder and other pervasive developmental disorders: J. Clin. Psychiatry 66 (suppl 10) 3-8. 
Freitag C.M (2007) The genetics of autistic disorders and its clinical relevance: a review of the literature. Mol Psychiatry 12 (1) 2-22.

Happe F. (1999). Understanding assets and deficits in autism; why success is more interesting than failure. Psychologist. 12911 pp. 5707.

Honda H., Shimizu Y, Rutter M. (2005). No effect of MMR withdrawal on the incidence of autism: A total population study, J. Child Psychol Psychiatry 46(6) 572-9.

Johnson C.P, Myers, S.M. Council on Children with Disabilities (2007). Identification and evaluation of children with autism spectrum disorders. Pediatrics 120 (5) 1183-215.

Kanner L. (1943). Autistic Disturbances of the effective contact. Nerv Child 2 217-50.

Kennedy Krieger institute (2003). Study reveals symptoms of autism are apparent in infancy. Baltimore.

Landa R. (2007). Early communication development and intervention for children with autism Retard Dev. Disabil. Res. Rev. 13 (1) 16 - 25.

Landa R.J (2008). Diagnosis of autism spectrum disorders in the first 3 years of life. Nat Clin Pract Neurol 4(3) 138-47.

Leskovec T. J., Rowles B. M., Findling R. L. (2008). Pharmacological treatment options for autism spectrum disorders in children and adolescents. Harv. Rev. Psychiatry 16(2) pp. 97-112.

London E. (2007). The role of the neurobiologist in redefining the diagnosis of autism. Brain Pathol 17(1) pp. 408-11.

Lord C., Cook E. H., Leventhal B. L., Amaral D. G. (2000). Autism spectrum disorders. Neuron 28(2) pp. 353

Montes G, Halterman J.S (2007). "Psychological functioning and coping among mothers with autism: A population - based study Pediatrics. 119 (5). NY.

Montes G, Halterman J.S (2008). Association of childhood autism spectrum disorder and loss of family income. Pediatrics 121 (4) 821 -6 retrieved from Wikipedia, the free encyclopedia.

Montiel-Nava C. Pena J. A. (2008). Epidemiological findings of pervasive development disorders in a Venezuelan study. Autism 12(2) 191202.

Myers S. M., Johnson C. P., Council on Children with Disabilities (2007). Management of children with autism spectrum disorders. Pediatrics 120 (5) pp. 1162-82.

National Institute of Neurological Disorders and Stroke (2006). Bethesda, National Institutes of Health 06-1877 
Newschaffer C. J., Croen L. A., Daniels J. (2007). The epidemiology of autism spectrum disorders. Amin Rev. Public. Health 28 235-58.

Newschaffer C. J., Kresch Curran I. K. (2003) Autism; an emerging public health problem. Public Health Rep; 118:393 - 9.

Newschaffer C. J. Falb M. D., Gurney J. G. (2005). National autism prevalence trends from United States special education data. Pediatrics; 115: 277 - 82.

Nwokolo O. M. (2007). 190,000 kids Suffer Brain Disorder Yearly, Daily Sun, Voice of the Nation.

Odebunmi A. (1989) Psychological Tests for Counselling and Health Management. Psychoeducational research productions, Ibadan.

Okey-Martins N. (2007) Autism in Nigeria: A brief on current situation. Lagos.

Oswald D. P., Sonenklar N. A. (2007). Medication use among children with autism spectrum disorders J. Child Adolesc. Psychopharmacol 17(3) 348-55.

Ozoji, E. (2002) The Challenges of Mainstreaming special Needs students in Post-Primary School in G. O. Akpu (ed.), Op. Cit. pp. 128 - 137.

Ozonoff S., Cathcart K (1998) Effectiveness of a home program intervention for young children with autism. J. Autism Dev. Disord. 28: $25-32$

Rice C., Baio J., Van Naarden Baraun K. Doermberg N. Meaney F. J., Kirby R. S. (2001) the ADDM Network. A public health collaboration for the surveillance of autism spectrum disorders (ASD). Paediatr Perinat Epidemiol. In Press

Tager-Flusberg H. Caronna E. (2007). Language disorders: autism and other pervasive development disorders. Pediatr. Clin. North Am. 54 (3) 469-81.

The Federal Republic of Nigeria (2004). National Policy on Education. Abuja: NERD

Wazana A, Bresnahan M, Kline J. (2007). The Autism epidemic: fact or artifact? J. Am. Acad. Child Adolesc. Psychiatry 46(6) 721-30.

World Health Organization (2006). Pervasive Developmental disorders. International Statistical Classification of Diseases and Related Health Problems, 10 th ed. (ICD-10). Retrieved on $2007-06-25$.

Yeargin-Allisopp M. Rice C. Karapurkar T., Doernberg N, Boyle C, Murphy C. (2003) Prevalence of Autism in a United States Metropolitan Area. JAMA. 289: 49 - 55. 